\title{
Multiculturalism in a Multilingual Society: Could That Be Possible?
}

\author{
Meryem Fati, Doctorate in Education \\ Mohammed V University-Souissi, Faculty of sciences of education, Rabat, Morocco
}

\begin{abstract}
Morocco is the land of multiculturalism. From childhood people are exposed to more than one language. However, this exposure brought loads of questions related to the nation's identity. Douglas Brown believed in his article Learning a Second language that 'second language learning in some respect involves the acquisition of a second identity'. In this respect, one wonders about the situation of learners who are exposed to more than two languages. Does this entail that they will have multiple identities and that they can function in multiple cultures?

Learning languages is a double-edged sword. On the one hand, it enables students to function in different societies and cross the boundary of language that could be for some a real trap. It helps them get exposed to other cultures and thus challenge some of their limited mono-cultural views and be citizens of the world. On the other hand, it could be the major factor behind having people who do not know how to fit in their own society. In addition, learners may have serious issues related to their own identity. Researchers in most parts of the world feel the need to challenge traditional educational approaches and come up with new ones that promote cultural awareness. It is commonly known that language and culture are interrelated; yet they often lack explicit understanding of this interrelationship. The lack of a clear concept of this interrelationship explains why there is a general dearth of appropriate techniques to teach language-culture, except through often old-fashioned and trivial activities.In this respect, how can we deal with cultures in a multilingual society? And how can we get our students to think locally but work globally?

Keywords: cultural awareness, EFL, language, multiculturalism, multilingualism,
\end{abstract}

\section{Submitted Date 19 June $2013 \quad$ Accepted Date: 24 June 2013}

\section{Introduction}

Morocco is the land of multilingualism and its linguistic situation is slightly complex. Most of people are exposed to many languages from their childhood. First comes Moroccan Arabic which is called 'Darija', Amazigh (it has different varieties), Hassania and standard Arabic that is mainly used in education . Then, comes the second language which is French and foreign languages that are namely: English, Spanish (sometimes stands as a second language especially in north of Morocco), German, Italian etc. Foreign languages are mostly used in business, education or tourism. Some people are born in families that speak darija, Amazigh and French and then they learn a foreign language at school. This is so impressive but at the same time especially in this era one wonders if those people are pure multilinguals and most importantly if they do not find any problems switching from one language to the other especially if we take into consideration its cultural element.

This is an exploratory study that is part of my doctoral research that is entitled "Investigation Into The Processes Underlying The Development Of Cross Cultural Awareness Through Language Education'. The aim of the research is to identify the processes that help Moroccan students develop cross-cultural awareness when learning a foreign language (English). As far as this article is concerned, it tries to handle the topic from another perspective. Its main aim is to know the abilities that Moroccan students develop when they learn a set of languages. The article also intends to see the role of education in transmitting a safe cultural content.

\section{Culture}

What is culture? How can we define it? Why is it dreadfully important to know major things about it while learning languages or delving into conversations that are interculturally- based? The word culture is both a broad and a many sided concept. It encompasses a multiplicity of meanings that are relevant in certain situations and thus you can not be limited to one definition. In the field of foreign language instruction a distinction should be made between big c Culture (high culture) and the small c culture (everyday culture). This is a very problematic view since it does not account for the changing nature of culture.

Many attempts have been done to define the word culture. All of them derived from experiences that authors lived. In addition, every definition was mainly matching a specific field of enquiry. The UNESCO 
describes culture as follows: the set of distinctive spiritual, material, intellectual and emotional features of society; it encompasses art, literature, lifestyles, ways of living together, value systems, traditions and beliefs (i.e., [1]). Edward Burnet Tyler has been honored as the father of anthropology. His definition of culture has been introduced in every book that deals with culture. He views culture as "complex whole which includes knowledge, belief, art, morals, law, custom, and any other capabilities and habits acquired by man as a member of society" (i.e., [2]). In fact, culture is a complex entity. It encloses many things that sometimes it can go beyond what the person's mind can think of. Tylors's attempt to define the word was acknowledged by many scholars and since his definition many scholars and writers from different fields tried to define this concept from different perspectives.

Culture can be viewed also as social markers that make people unique from each other based on their country of origin, race, or languages that they were born with. Although people are different because of their cultures, languages, races, religions, and other aspects; there are universal values and norms across human societies. The challenges of social work research are to investigate the similarities in the midst of obvious differences and diversity (i.e., [3]).. This definition could be valid in the context of foreign language learning. People from different countries have different cultures and ways of viewing the world. This mainly results in the appearance of a certain diversity that may either constitute a boundary or a way of transcending differences and thus being tolerant towards all cultures. Geertz' (1975) defines culture as:

A historically transmitted pattern of meanings embodied in symbols, a system of inherited conceptions expressed in a symbolic form by means of which men communicate, perpetuate, and develop their knowledge about attitude towards life. (i.e., [4]).

The way one perceives the world is linked to the shared patterns of cultural and social meanings that are diffused from one generation to the other and shared by the community. Shore provided a cognitive anthropological perspective on culture. He views culture as "an extensive and heterogeneous collection of 'models', models that exist both as public artifacts 'in the world' and as cognitive constructs 'in the mind' of members of a community" (i.e., [5]).. To make his definition more explicit he claims that "important advantage of conceiving of culture as a stock of conventional models is that the very notion of models provides a bridge between the empiricist concept of culture as 'objects' and the cognitive concept of culture as form of knowledge (or, more pretentiously, as mental representations)" (i.e., [6]).

Shore is known by his distinction between conventional mental models and personal mental models. The conventional mental models encompass the community's shared cognitive resources of how to make meaning. Greeting could be the best illustration of that model. People greet in different ways in different countries and cultures. Sometimes this convention functions as a sociocultural constraint since "to gain motivational force in a community, these models must be reinscribed in each generation in the minds of its members" (i.e., [7]). The personal mental models are derived from personal experience. "They are not shared in their details by others [of a community]" (i.e., [8]).. People differ in their way of viewing things. Each one of us view certain facts from his/her own perspectives. The two mental models are interrelated because the personal mental models are shaped through the internalization of the conventional models during socialization.

Culture and language are interrelated since this later plays a huge role in the formation of concepts. Lantolf (1999) points out "the entities designated by the same word in one culture are not necessarily the entities labeled by a corresponding word (assuming a corresponding word even exists) in another culture" (i.e., [9]) Language learning goes beyond the acquisition of linguistic forms. It is mainly about creating new meanings, new realities and viewing the world from a different perspective. However, when leaning a language what aspect of culture is it covered and how is it presented to the language learners?

\section{Language and culture}

Language is a set of symbols and signs that are governed by rules that are shared by the community in order to acquire its social function that is communication. While culture, generally speaking, could be seen as a set of values, norms, beliefs, attitudes, and artifacts that are shared by a certain community. During the last decades, there has been an argument over the interrelation of language and culture. As a result, the majority of scholars claimed that learning a language is integral to the learning of its culture. There is a solid recognition in pertinent literature that teaching a language can not be isolated from the teaching of its culture. Some anthropologists have adeptly observed that culture would not be possible without language. Seelye said that the study of language can not be divorced from the study of culture, and vice-versa (i.e., [10]). Language is the keystone of culture. In the broad sense, language is the symbolic representation of people, and it comprises their historical and cultural backgrounds as well as their approach to life and their ways of living and thinking.

Learning a language in isolation of its cultural roots, prevents one from becoming socialized into its contextual use. Knowledge of linguistic structure alone does not carry with it any special insight into the political, social, religious, or economic system. Or even insight into when you should talk and when you should not (i.e., [11]). The major aim behind combining the learning of culture and language is to give students the 
ability to function beyond the classroom setting. Language is a social practice. It is no more perceived as a structural, or grammatical system but as communication among people.

When learning a foreign language, learners are supposed to acquire four skills that are reading, listening, speaking, and writing. Nevertheless, acquiring cultural knowledge of the target language is most of the time called the fifth skill. Modern pedagogical approaches call for the integration of this skill within the other ones so as to guarantee a safe exposure to culture. Exposing learners to cultural differences along with the structural differences of the native and the target language is vital since it helps them develop their cultural awareness. Bryam, Gribkov and Starkey said that the aims of language teaching are to develop both linguistic and cultural competence, what is named as intercultural communicative competence. They maintained that in that way learners become able to understand and accept people from different cultures as individuals with other perspectives, values and behaviors (i.e., [12]).

Nowadays using a foreign language effectively in human interactions across cultures is of a great importance. In order to participate in a variety of social and cultural contexts the knowledge of the society and culture of the community, in which the language is spoken, is necessary (i.e., [13]). One of the basic aims of learning languages is to develop intercultural competence. Kramsch (1998) defines intercultural competence as a combination of attitudes, knowledge, skills, sub-skills, awareness and self-awareness:

- Attitudes, basis of intercultural competence: openness to and interest in other people's values, behaviors and beliefs, willingness to admit diversity;

- Knowledge of differences in things and practices, an ability to see them in a positive light rather than as differences;

- Skills of interpreting and relating: an ability to recognize, understand, explain differences and relate them to one's own reality;

- Skills of discovery and interaction: knowledge of how to acquire new knowledge, attitudes and skills from other people and an ability to use them in interactions;

- Skills of comparison: an ability to analyze, compare and evaluate others' behaviors, beliefs and meanings by contrasting them to one's own, emphatic and analytical understanding of the similarities and divergences between one's own culture and the culture of others;

- Cultural awareness: awareness of cultural variety, an ability to depart from ethnocentricity (i.e., [14]).

Foreign language learning requires significantly more amount of foreign culture learning, now that 'learning new languages opens students' minds to the ways of other people and increases the opportunities for cross-cultural understanding' (i.e., [15]). Overtly or covertly, culture has often been taught in the foreign language classroom but not as formally emphasized as it should be.

Language subjects break with the traditional view that 'language' and 'culture' constitute an inseparable whole and that language teaching must therefore work for maximum integration between teaching the target language and teaching in the target language culture (or, in other words, culture and society in the target language countries). Language subjects must work on the theory that the relation between language and culture is complex and multidimensional, and that linguistic practice and other cultural practice are parts of more or less comprehensive processes- also transnational and potentially global processes (i.e., [16]). Success in learning a second or even third language is partially related to the acquisition of the cultural baggage that is carried along with any linguistic system (i.e., [17]).

Culture can lead to different interpretations and reaction to language. The students' ability to comprehend and communicate in a foreign language is highly dependent on the culture background knowledge, and the deficiency of this knowledge is most likely to cause their poor mastery of language (i.e., [18]). Language and culture are so intricately related that their boundaries, if any, are extremely blurred and it is difficult to become aware of the assumptions and expectations that we hold, though (i.e., [19]).

It could be said that a language is part of a culture and culture is part of language; the two are intricately interwoven so that one can not separate the two without losing the significance of either language or culture.

\section{Teaching languaculture}

Teaching language and culture as a one component has been the aim of education recently. Language reflects culture; hence it is crucial to incorporate them together in the materials (i.e., [20]). Traditional thought in foreign language education has limited the teaching of culture to the transmission of information about the people of the target country, and about their general attitudes and world views (i.e., [21]). However, according to Valette (1996), culture in the language classroom includes two major components: the anthropological or sociological culture (values, attitudes, customs and daily activities of people, their ways of thinking, etc.) and the history or civilization, traditionally understood as geography, history and the achievements in the sciences 
and the arts (i.e., [21]). In this sense, when teaching culture the professors should bear in their minds that they need to cover basically most of the above mentioned aspects. Anthropologically speaking, the presence of culture in EFL classes should take into consideration, especially during the first semesters, that students come to the classroom with certain beliefs and perceptions. Thus, the professors' task would be to find a way to accommodate the native language culture and the target language culture. Language teaching theorists have emphasized the importance of language learning in gaining knowledge about a country and its people (i.e., [22]). In addition, subjects should have a socio cultural perspective since a foreign language learners should learn not only how to express themselves in the foreign language but also be aware of the intentions, expectations and behavior of a native speaker, therefore, he/ she needs to get acquainted with cultural differences, world views and behaviors (i.e., [23]). Culture has an influence on every aspect of language: lexical study, syntactical and grammatical study, literature and reading, composition and essay writing. Santos and Suleiman claim that the socio-linguistic aspects of Arabic differ from those of the English language (i.e., [24]).

They explain this point as follows: 'some of these (sociolinguistic) features usually transfer to English in an inappropriate manner. For example, the depth of questioning about family affairs, health, and other private matters are culturally incompatible. Jokes are also culture-bound; what is humorous to an Arab might be outrageous to an American and vise versa. In fact, these are things that students become aware of at later stages of their language learning especially if they have an opportunity to meet native speakers or travel to English speaking countries.

Language and culture are integral to the experience of learning. In learning in any area and, indeed, in learning language itself, learners depend on language. Learning involves the reciprocal interpretation of meaning in and through interaction with people and texts, and all interpretation is linguistic. However, Angela Scarino says that language is more than just a container for information, for it brings with it cultural histories that structure the dialogue of learning among people and their personal engagement with the world (i.e., [25]).

Although it is understandable that culture cannot be learned or acquired In a few lessons about celebrations or traditions of the country where the language is spoken, cultural awareness may be developed in a spontaneous way as well, e.g., when learners encounter specific vocabulary while reading a piece of work or when questions pertaining to the target culture are raised by learners, discussed and compared to the home culture. Sometimes students' behavior or reaction towards a certain situation can lead to a certain discussion in the class that could be culturally loaded even if it is not really apparent in the surface. During the last decade a general rethinking of the role of language as social practice has taken place that suggests new ways of looking at the teaching of language and culture (i.e., [25]). Three lines of thought emerge in particular:

- Establishing a "sphere of interculturality": understanding a foreign culture requires outing that culture in relation with one's own. Meaning is relational. An intercultural approach to the teaching of culture includes a reflection both on the target and on the native culture.

- Teaching culture as an interpersonal process: if meaning emerges through social interaction, then it is pointless to try and teach fixed, normative phenomena of language use. Rather we should as many educators advocate, (abdallah-pretceille 1983, muller-jacquier 1986) replace the presentation/ prescription of cultural facts and behaviors by the teaching of a process that applies itself to understanding foreigness or 'otherness' (i.e., [26]). As the french educator Zarat 1986 advocates, teachers should be encouraged to recognize the rupture points in he logic of the explanations brought forth by their students in order to bring cross-cultural aspects of communication to the fore (i.e., [27]).

- Crossing disciplinary boundaries: my words: encouraging language teachers to broaden their reading to include besides literature, anthropology sociology and ethnography. 206

A teacher's role is not to impart facts about the target culture but to help students gain skills to understand phenomena in the target culture and thus be prepared for various situations (i.e., [28]). Apart from developing the students' communicative (dialogic) competence in the target language, language teaching ought also as far as possible to enable students to develop into multilingually and multiculturally aware world citizens (i.e., [29]). This should be done in the stated way since the majority of students do not have the ability to travel and live in the culture that they are studying. In this manner, the Classroom becomes the substitute of the real world (i.e., [30]). This is the only location in which cultural contact can be made. Within the context of foreign language teaching, knowledge about other cultures, openness and empathy toward other cultures, critical involvement with intercultural topics, the readiness to put one's own convictions into perspective, and the ability to deal with people from different cultures are to be promoted to induce sound cultural awareness which need to be the major aim of EFL classes (i.e., [31]).

Kubota (2003) has proposed the employment of four key concepts in analyzing culture for the purposes of second or foreign language education (i.e., [32]): A focus on descriptive rather than prescriptive understanding of culture (1), a focus on diversity within a culture (2), and culture's dynamic nature (3), and a focus on the discursive construction of culture (4) by which she means that our knowledge about the experiences 
of culture are constructed in discourses. In teaching culture, Ned Seelye (1988) provides a framework for facilitating the development of cross-cultural communication skills. Within this framework we find 'seven goals of cultural instruction' (i.e., [33]): 1- to help students understand that all people exhibit culturally conditioned behaviours; 2- to help students know that social variables such as age, sex and social class affect the way people speak and behave; 3- to help students become more aware of conventional behavior in common situations in the target culture; 4- to help students increase their awareness of the connotations that words and phrases may have; 5- to help students develop the ability to evaluate the target culture; 6- to help students develop the necessary skills to locate and organize information about the target culture; 7- to stimulate the students' intellectual curiosity about the target culture, and to encourage empathy towards its people.

Teaching culture as difference was seen as one of the ways of integrating culture in language classes. National identities are being questioned all over the world, the temptation is great to view culture only in terms of national traits. However, traditional questions like what does it mean to be Moroccan become increasingly difficult to answer. It can not be said that the national characteristics are unimportant, but they can not be adduced without further specification of other cultural factors such as age, gender, regional origin, ethnic background, and social class. National traits are but one of the many aspects of a person's 'culture'.

\section{Conclusion}

Communication in an additional language means entering a new world of meanings without leaving behind one's own world, that is captured in the first language or languages. The first language provides a constant reference point for understanding the world of meanings made available in the language being learned. In learning an additional language, students are simultaneously and equally in the world of their first language(s) and the world of the new language that they are learning, with the possibility of constantly moving backward and forward across the space between the two languages and their respective worlds of meanings. They do so from their experiential situatedness in their own language and culture, as do all others with whom they communicate. They appreciate that, in communication, they interpret people and the world through the frame of reference of their cumulative experience within their own language and culture (i.e., [34]). Kramsh (2003) adds that culture is seen not as product, but as a process of meaning ascription through language use in various subfields of applied linguistics culture is perceived as (1) ways of categorizing, i.e. as belief or ideology, as (2) ways of interacting, i.e. as habitus or socialization, and (3) as ways of belonging, i.e. as social and cultural identity (i.e., [35]).

\section{References}

[1] Unesco, (2011), Languages: Conflict or Coexistence?, http://unesdoc.unesco.org Accessed 21/09/2011.

[2] E.B. Tylor, The origins of Culture, (1958), New York: Harper and Row, United Nations (2002), International migration report 2002 (document No. ESA/P/WP.178), New York: Author. P 20

[3] T. V. Tran, Developing Cross-cultural measurement (Oxford university press, P.5, 2009)

[4] C. Geertz, The interpretation of culture (London: Hutchinson, P 89, 1975)

[5] B. Shore, Culture in mind: Cognition, culture and the problem of meaning (Oxford: Oxford University Press, P 44, 1996)

[6] Ibid. P 44

[7] Ibid. P 47

[8] Ibid. P 47

[9] J. Lantolf, Second Culture Acquisition: Cognitive Consideration (In E. Hinkel Culture in second language teaching and learning, Cambridge: Cambridge University Press, P 8, 1999)

[10] H. Seelye, Teaching Culture: Strategies for Interculturral Communication (USA: National Textbook Company 1993)

[11] Ibid p 57

[12] M. Bryam, B. Gribkov, H.Starkey, Developing the Intercultural Dimension in Language Teaching. Council of Europe, Strasbourg. http://www.coe.int/t/dg4/linguistic/Source/Guide_dimintercult_En.pdf, 2002

[13] The common European Framework of Reference for Languages: Learning, Teaching, Assessment, Cambridge University Press, http://www.coe.int/t/dg4/linguistic/sources/Framework_En.pdf, 2001

[14] C. Kramsch, Language and Culture (Oxford: Oxford University Press, 1998)

[15] J. Citron, Can Cross-Cultural Understanding Aid Second Language Acquisition? Toward a Theory of Ethno-Lingual Relativity (Hispania, 1995, p 78)

[16] K. Risager, Language and Culture Pedagogy: From a National to a Transnational Paradigm (Published by Multilingual Matters Limited, Clevedon, GBR, 2007, P 2)

[17] L. Damen, Culture learning: the fifth dimension in the language classroom (Addison -wesley publishing company, 1987)

[18] Z. Bao-he, How to enhance cross-cultural awareness in TEFL, cross cultural communication (vol. 6, no. 2, 2010, pp. 100-104)

[19] C. Kramsch, Language and Culture (Oxford: Oxford University Press, 1998)

[20] N. Fairclough, Critical Language Awareness. (USA, New York, Longman, 1992, p 6)

[21] C. kramsh, Context and Culture in Language Teaching (Oxford University Press, 1993, p 205)

[22] R. M. Valette, The Culture Test. In J. M. Valde, Culture Bound: Bridging the Cultural Gap In Language Teaching (New York: Cambridge University Press, 1996)

[23] H. H. Stern, Fundamental Concepts of Language Teaching (UK, Oxford: Oxford University Press, 1983, P 247)

[24] R. M. Valette, The Culture Test. In J. M. Valde, Culture Bound:Bridging the Cultural Gap In Language Teaching (New York: Cambridge University Press, 1996)

[25] S. Santos, \& M. Suleiman, Teaching English to Arabic-speaking students: cultural and linguistic considerations, Proceedings of the National Annual Association for Bilingual Education Conferences, Tucson, Az, 1993, p 175 
[26] A. Scarino, Assessing Intercultural Capability in Learning Languages: A Renewed Understanding of Language, Culture, Learning, and the Nature of Assessment (The Modern Language Journal, 2010, P. 327)

[27] C. kramsh, Context and Culture in Language Teaching (Oxford University Press, 1993)

[28] M. Abdallah pretceille, la perception de l'autre: Point d'appui de l'approche interculturelle, le francais dans le monde ( 1983, P 181)

[29] G. Zarat, Enseigner une Culture Etrangere (Paris: Hachette, 1987)

[30] A. Omaggio, Teaching Language in Context (Boston, MA : Heinle and Heinle, 1993)

[31] K. Risager, Language and Culture Pedagogy: From a National to a Transnational Paradigm (Published by Multilingual Matters Limited, Clevedon, GBR, 2007, P 1)

[32] L. Damen, Culture learning: the fifth dimension in the language classroom (Addison-wesley publishing company, 1987, p 7)

[33] M. Zaid, Language, Identity, and the Nativization of English: Is it the end of standard English? (Minia College of Arts Journal, 8 (2), 2008, 20-43)

[34] R. Kubota, Critical perspectives of culture in second language education, Paper presented within a series on Language, Culture, and Identity at the UBC Centre for Intercultural Language Studies. Vancouver, Canada, February 2003

[35] N. Seelye, Teaching Culture (Lincolnwood, Il.: National Textbook Company, 1988) from B. Tomalin, S. Stempleski, Cultural Awareness (Resource Books for Teachers, Seies editor Alan Maley, Oxford University Press, 1993, p.8)

[36] A. Scarino, Assessing Intercultural Capability in Learning Languages: A Renewed Understanding of Language, Culture, Learning, and the Nature of Assessment, The Modern Language Journal, 94. 2010, P. 327

[37] C.Kramsch, Language and culture revisited. Paper presented within a series on Language, Culture, and Identity at the UBC Centre for Intercultural Language Studies, Vancouver, Canada, October 2003, P 64 